\title{
Exploring Skills and Competencies of Innovation: the Case for a Qualitative Methodology
}

\author{
Mónica Martínez-Gómez ${ }^{1}$, Manuel Marí-Benlloch², and Juan A. Marin-Garcia ${ }^{3}$
}

\begin{abstract}
This paper highlights a qualitative methodology to detect the most relevant behaviours and skills to be included in assessment innovation competency of higher education students. Innovation is a complex process that comprises several competencies, such as, perception of opportunities, ideas generation and evaluation, action plans, cooperation and risk. It is considered one of the most competitive advantage in determining the success or failure of a company in the global market. We used the INCODE-ICB-v6 questionnaire as the measurement instrument of innovation which measures the innovation construct with a series of 25 items, grouped into three categories: individual, teamwork and network. The items on our version of the questionnaire INCODE-ICB-v6 are in a different order with respect to the original questionnaire. We applied a qualitative explorative analysis via a distance-based affinity diagram, where the students can group the proposed items of the questionnaire. Our affinity diagramming process consists of two stages. First, the interviewed group the items in the category they think is best. Then, we represent items in a perceptual map using a non-metric multidimensional scaling (MDS). MDS analyses were carried out with two databases, one for four categories model and second for up to ten categories model. The results of multidimensional scaling confirm the structure of these three components in both models, for four and up to ten categories.
\end{abstract}

Keywords - Innovation competency, Multivariate analysis, nonmetric multidimensional scaling, INCODE questionnaire.

\section{INTRODUCTION}

$\mathrm{D}$ URING the last few years developing students Skills by incorporating better academic education processes to allow them a greatest success in labour market has become a main aim of the European Higher Education Area (EHEA).

Currently, one of the prerequisites required by companies is that professionals improve their qualifications $\mathrm{m}$ transversal skills. Transversal skills are the disciplines and capabilities that can be used for all professions. In this context, innovation appears as a source of competitive advantage in the business world. Innovation capability is the most important determinant

Mónica Martínez-Gómez, is with Departamento de Estadística e Investigación Operativa aplicadas y Calidad Universitat Politècnica de Valencia, València, (Spain). (Phone: +34 96 3877007, e-mail: momargo@eio.upv.es).

Manuel Marí-Benlloch, is with Departamento de Estadística e Investigación Operativa aplicadas y Calidad Universitat Politècnica de Valencia, València, (Spain), (e-mail: mamaben@eio.upv.es).

Juan A. Marin-Garcia, is with ROGLE-DOE-Universitat Politécnica de Valencia, Valencia, (Spain), (e-mail:jmarin@omp.upv.es). of firm performance [1]. Innovation is important both at the personal and at the organizational level. Innovation represents the strategic process for competitiveness. Thus, people's training to develop the competence of innovation is a must for all companies which want to be competitive.

In the business word innovation is similar as receive widespread attention [2], however, it is not easy to define innovation, since it implies the acquisition of different capabilities and capacities among which the following are noteworthy: creativity (generation of ideas, critical thinking, synthesis (reorganization ability), creative problem-solving (using new ideas to solve problems as a leader or entrepreneur), problem identification (clarify the real nature and the cause of the problems, search continuous improvement, collect information), independent thinking, be open to new ideas, focus on research, team work, forwardlooking approach, among others and which have been discussed in different papers [3], [4], [5], [6].

There is a lot of bibliography written about innovation skills. [7] is a summer of 44 papers collected from different reviews. They found 12 innovations models that present a different degree of specified development and validation. Therefore, there is not one exclusive classification to group the different capabilities or characteristics that make up innovation [4], [7], [8], [9] and there is much debate on the instrument used in order to identify and validate the acquisition of innovation skills, which means a lack of knowledge on the efficiency of teaching and learning methods.

A model specifically centred on innovation competencies will be followed in this project [11], [12], [6], [13] and which has been reproduced in one of the more widely used instrument during the last few years to measure that competence: the Innovation Competencies Barometer (INCODE-ICv6 Barometer) (IBC), which stem from the conception of innovation as a construct (Figure 1) that is based on three dimensions: individual, interpersonal and networking aspects, following the model proposed by Penttila and Kairisto-Mertanene [12], [6].

With regard to the certification of the components of innovation competence, no qualitative method has been regulated to acquire and assess the skills and capacities involved. Prior studies have validated the measuring toot, the ICB, but with quantitative analysis. The lack of a formal quantitative system of identification and validation the tool to measure innovation competence can probably apply to other 
generic competences that are included in current new degree programs. For this reason, the main objective of this paper is to advocate that qualitative research toots can replace and merge with quantitative ones in order to simplify the task of gathering and processing information, according with [14].
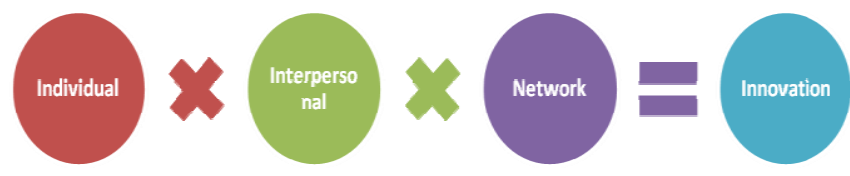

Fig. 1. Model of innovation competence construction based on Penttilä and Kairisto-Mertanene $(2011 ; 2012)$

\section{A. Purpose and Contributions of Present Study}

Our aim is to apply an affinity diagram to detect the most relevant behaviours and skills that assessment innovation competency of higher education students.

Affinity diagramming is a powerful method for encouraging and capturing lateral thinking in a group environment [15]. Affinity-diagram activities also help teams to group and link their collective thoughts into a clear and understandable structure [16]. Affinity diagram is usually conducted using pens, sticky notes and whiteboard. However, in recent years many studies have been conducted to development and build solutions to improve the effectiveness group brainstorming or affinity diagrams using electronic system [17], [18], [19], [16], [20].

Although qualitative research has been critiqued too often by lacking in scholarly rigor, nowadays many researches contradict it [21], [22]. We have been unable to locate any studies that have validated INCOME questionnaire with a multidimensional qualitative technique. So, there is a lack of empirical studies that have addressed if affinity diagram can be applied to validate the IBC and so to verify if acquire innovation competence by students of higher education is related to experiment with new teaching alternatives associated with active methodologies.

This study is structured as follows. First, we present the research methodology. Second, the results obtained. Finally, this paper concludes with the main reflection of findings achieved in our analysis, their limitations and recommendations for further research.

\section{II.METHODS}

\section{A. Participants}

Data can be collected by the researches $m$ different ways. Rankings, ratings, BARS and BOS and paired comparisons [23]. In this paper we will focus on the second method because the construction of the ICB presupposes that rates who apply this instrument to assess innovation competence are able to secure consistent and accurate results [23].

The total sample was constituted by 918 students of a Massive Online Open Courses (MOOC) from a Spanish public university, who will complete one version of the questionnaire (INCODE-ICB-v6) classifring the 25 items related to innovation competencies. The items on this version of the questionnaire INCODE-ICB-v6 are in a different order with respect to the original questionnaire, where they are ordered in blocks: individual, interpersonal and network. Thus, a random organization of the items $\mathrm{m}$ the questionnaire prevents the bias of a certain cluster.

The respondents were then divided in two groups. The first group, made up of 458 students, was required to freely classilr the 25 items of the questionnaire into four categories, which had to be labelled by them. The second group was constituted by 460 respondents, which were required to classify the same 25 items, but in this case they had to do it freely in a maximum of 10 categories, which they also had to label.

Thus, in principle, there are not any categories in which to classify the items and the respondents are completely free to express their criteria of association and similarity among the items on the questionnaire related to their perception about the concept of innovation.

\section{B. Instrument}

We selected the INCODE-ICB-v6 questionnaire [23], [4], which measures the innovation construct with a series of 25 questions, grouped into three categories (Individual, Interpersonal - teamwork - and Networking). Responses were given a score of between 1 and 5 ( $1=$ major improvement needed; $5=$ excellent).

Due to limitations of space, we are unable to list the items of the INCOD-ICB-v6 questionnaire in this paper, but requests can be made via email for a copy of the questionnaire in either Spanish or English.

\section{C.Methodology}

Affinity diagramming is a technique used to externalize, make sense of, and organize large amounts of unstructured and dissimilar qualitative data.

In this study we develop qualitative explorative analysis as an optional tool to quantitative techniques for validating questionnaires via a distance-based affinity analysis, where individuals can group the proposed items of the questionnaire into the categories they think transversal innovation competence is better described. Our affinity diagramming process consists of two stages. First, the respondents group the items in the category they think is best. Then, we represent items in a perceptual map using non-metric multidimensional scaling analysis (MDA).

We used non-metric multidimensional scaling analysis as a multidimensional analysis to obtain the perceptual map.

The procedure allows the respondents to gain a perceived image related to a set of objects and interpret the dimensions of this space in attributes or dimensions interesting for the researcher, based on comparisons among objects. The aim is to understand the respondents' perceptions on the attributes of the study objects and plot the results on a perceptual map, transforming the similarity assessment among objects perceived by the respondents in distances between objects, being the researcher's art and science to interpret the dimensions of said perceptual map and assign it the relevant attributes [24].

In our case, the objects match up with items in the questionnaire and the purpose is to identify the respondents' judgment on the concept of innovation by searching the 
perceived attributes in the dimensions of the perceptual map obtained by correspondence analysis. In order to do this, the similarity comparisons among the items on the questionnaire carried out by the respondents shall be transformed in distances among said items which will be represented in the perceptual map.

\section{RESULTS}

In order to analyse the internal structure of the data collected from the questionnaire, we have used the Nonmetric Multidimensional Scaling (PROXSCAL). The procedure for this technique is the optimal position determination among objects. From a desired initial dimensionality, configurations are obtained by calculating the distances among objects and comparing the relationships observed against the relationships estimated with an adjustment for measurement. The configurations are a distribution of the set of objects (dots) on the coordinate axes which make up the dimensions and which can be represented on a "perceptual map" [24]. Once the configuration is found, the distances among objects (dij) in the configuration are compared with the distance measurements (eij) of similarity judgements. These two distances are then composed using an adjustment for measurement, called stress measurement. The directions in which a higher adjustment can be obtained in order to reach a configuration with a satisfactory stress measurement and with the lowest possible dimensionality are set out below.

Kruskal's stress is a measure proposed to determine the adjustment of a model:

$$
\begin{aligned}
& \text { Kruskal's Stress = sqr [(dij - eij }) 2 /(\mathrm{dij}-\mathrm{dm}) 2] \\
& \text { where, } \\
& \mathrm{dm}=\text { the average distance on the map }\left(\sum \mathrm{dij} / \mathrm{n}\right) \\
& \mathrm{dij}=\text { distance obtained from the similarity data } \\
& \text { eij= original distances provided by the respondents. }
\end{aligned}
$$

Practically all the individuals responded to all 25 items on the questionnaire, so any missing values are not due to the characteristics of an item, nor do they present a problem for the data collected as a whole.

The non-metric multidimensional scaling was carried out with two databases, one for four categories model and second for up to ten categories model.

In order to determine the similarity among items perceived by the respondents, the frequencies with which each item was classified into a category together with other item were calculated, that is to say, the number of times the respondents placed those two items into the same category. The absolute frequencies of similarity among items for each one of the groups are shown in figures 2 and 3.

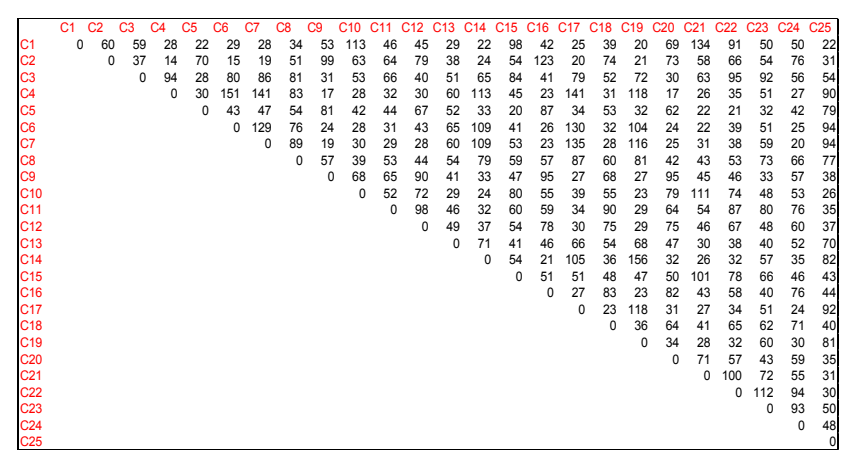

Fig 2. Association frequencies between items for the group of four categories.

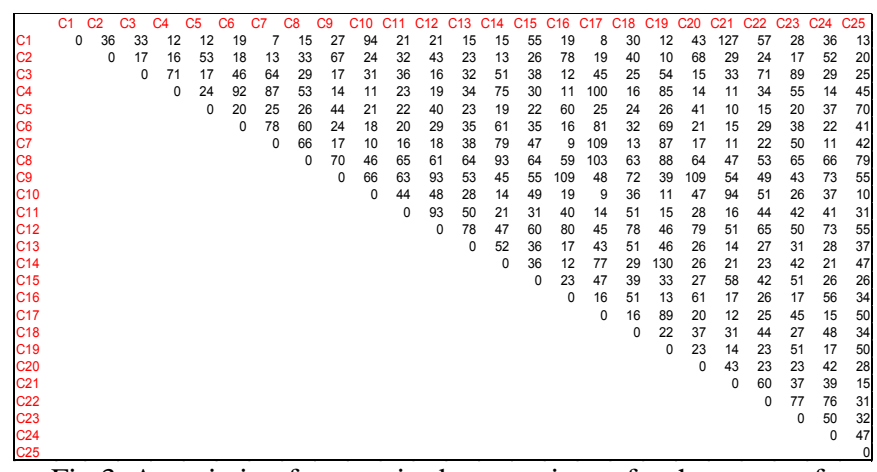

Fig 3. Association frequencies between items for the group of ten categories.

\section{A. Multidimensional scaling: four categories models}

In table 1 , we can see that stress and measurements for adjustment indicate the efficiency with which the distances of the solution get closer to the original distances.

TABLE I

MeAsures Of Stress AND AdJustment For THE MOdEL 4 CATEGORIES

\begin{tabular}{lr} 
Normalized raw stress &, 01947 \\
Stress-I &, $13955^{\mathrm{a}}$ \\
Stress-II &, $31831^{\mathrm{a}}$ \\
S-Stress &, $03720^{\mathrm{b}}$ \\
Told dispersion (D.A.F.) &, 98053 \\
Tucker consistency coefficient &, 99022 \\
\hline Note: PROXSCAL minimizes normalized stress raw. \\
a.Optimal scaling factor $=1,020$ \\
b.Optimal scaling factor $=, 996$
\end{tabular}

In the four categories model, each of the stress statistics measure the mismatch of the data, so stress values are close to 0 (Normalized raw stress 0.01947). On the other side, the explained dispersion and Tucker's consistency coefficient measure the adjustment of the model and, in our case, these measurements for adjustment get closer to value 1 (Tucker consistency coefficient 0,99022 ). All of this means we are before an excellent solution.

The perceptual map obtained for the first group of respondents of four categories is shown below in figure 4 . 


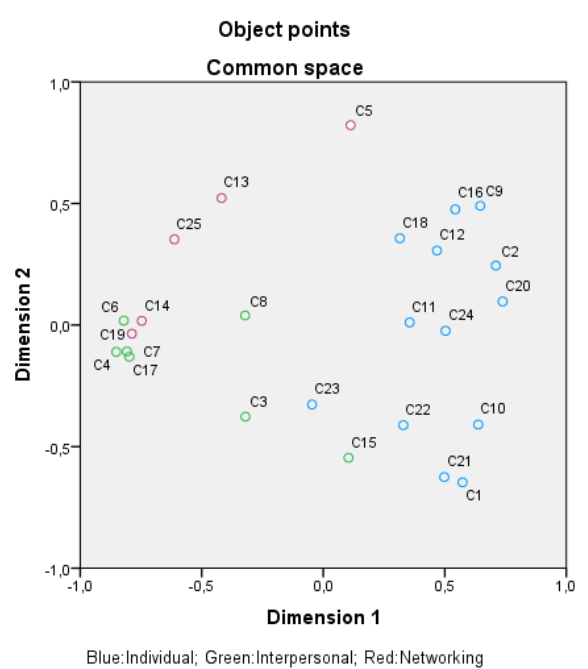

Fig 4. Bidimensional representation of the multiple correspondence analysis for four categories

The chart on figure 4 shows the two first dimensions related to the 25 items of the questionnaire. The items have been coloured according to the three components supposed for innovation (individual, interpersonal and network). As we can observe in the map, the items corresponding to the individual component, in blue, are clearly grouped, except item 23 . The items of the interpersonal component, in green, present a very compact grouping made up of items $(4,6,7,17)$ with a clear approach to items 14 and 19 which belong to the networking component. On the other hand, item 8 is isolated from the rest of items, in the centre of the common space and items 3 and 15 seem to be approaching to other items of the individual component (22 and 23). Meanwhile, the items of the networking component 13, 25 and 5 are to be found in the left top space creating a dispersed association indeed far from the rest of items.

\section{B. Multidimensional scaling: model with up to ten categories}

In table 2, we can see stress values and measurements for adjustment, which indicate the efficiency with which the distances of the solution get closer to the original distances. In the up to ten categories model, each of the stress statistics measure the mismatch of the data, so stress values are close to 0 (Normalized raw stress 0.03222 ). The explained dispersion and Tucker's consistency coefficient measure the adjustment of the model and get closer to value 1 (Tucker consistency coefficient 0.98376). All of this means we are before an excellent solution.

The map on figure 5 shows the two first dimensions related to the 25 items of the questionnaire. As in the case of four categories, items have been coloured according to the three components supposed for innovation. As we can observe in the map, the items corresponding to the individual component, in blue, are clearly grouped, except item 23 . The items of the interpersonal component, in green, present two groupings, except item 8 which is isolated. On one hand, the grouping ( 7 , $4,6,17)$ shows a clear approach to items 14 and 19 which belong to the networking component. On the other hand, a second grouping $(3,15,22)$ which is associated to item 23 of the individual component. Finally, the items of the networking component 13,25 and 5 are to be found in the top space creating a dispersed association indeed far from the rest of items in other components (individual and interpersonal).

TABLE II

MeAsures Of StRESS AND AdJUSTMENT For THE Model Up To 10 CATEGORIES

\begin{tabular}{lr}
\hline Normalized raw stress &, 03222 \\
Stress-I &, $17949^{\mathrm{a}}$ \\
Stress-II &, $42954^{\mathrm{a}}$ \\
S-Stress &, $06183^{\mathrm{b}}$ \\
Told dispersion (D.A.F.) &, 96778 \\
Tucker consistency coefficient &, 98376 \\
\hline Note: PROXSCAL minimizes normalized stress raw. & \\
a.Optimal scaling factor $=1,033$ & \\
b.Optimal scaling factor $=, 992$ &
\end{tabular}

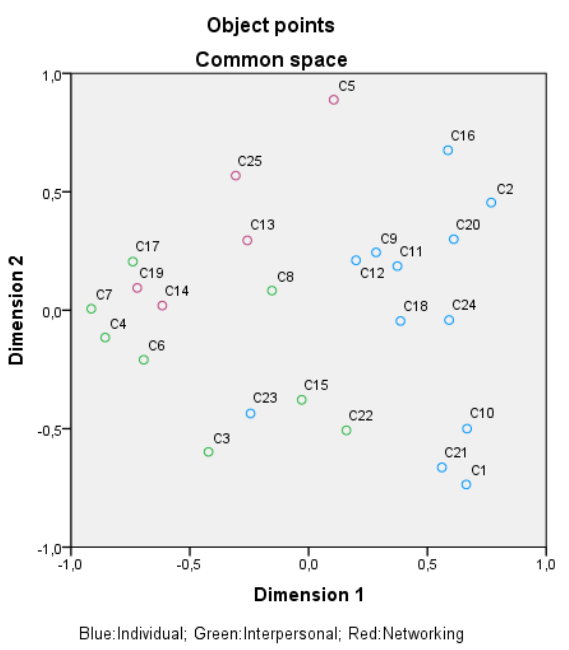

Fig 5. Bidimensional Representation of the Multiple Correspondence Analysis For Up 10 Categories

\section{CONCLUSION}

The purpose of our study is to evaluate if affinity diagram can be used to validate questionnaires as an alternative to the quantitative techniques. The research extends the work proposed in [25] lo validate innovation competence in higher education student's with quantitative analysis, presenting additional qualitative evidence in support of the instrument's relevance in actual settings. The paper, thus makes a significant contribution because the qualitative analysis to validate questionnaires could be used in surveys in many areas, such as management, business and not only in higher education. Results shows the qualitative validation of INCODE questionnaire to assessment the innovation competency of university students.

The internal consistency of theorist components of innovation is high in both models, for four and up to ten categories. Besides, the instrument has been validated as reflective and formative measurement model with quantitative techniques, empirical results of multidimensional scale confirms the structure of these three components (individual, interpersonal and networking), although some unsettled items were detected, in particular items $\mathrm{C} 3, \mathrm{C} 8, \mathrm{C} 15$ y C23 because 
they are away from their theorist related items.

But in any case, the internal measurement of the innovation competency is maintained. These findings are useful for researchers since they add the first sample in which the validation of a competency is developed with qualitative techniques and results are according with other qualitative techniques, like Structural Model Equation (SEM) or Partial Least Squared (PLS).

Results over the technical characteristics of the instrument, suggest real application for the improvement of measurement innovative competency.

Through this study we have contributed lo emerging literature of innovation competences. We have introduced a complementary qualitative analysis to validate the measurement tool, the IBC. Additionally, we have studied the influence of different categories models.

There were of course, limitations lo this study. As stated previously, we used a student sample with a specific questionnaire and the generalization to other questionnaire, or population, should be proved with specific data.

\section{ACKNOWLEDGMENT}

This paper has been written with financial support from two Projects:

GVA/20161004: Project of Conselleria d'Educació, Investigació, Cultura i Esport de la Generalitat Valenciana a través del proyecto "Validación de la competencia transversal de innovación mediante un modelo de medida formativo".

FINCODA: "Project 554493-EPP-1-2014-1-FIEPPKA2KA" (The European Commission support for the production of this publication does not constitute an endorsement of the contents which reflects the views only of the authors, and the Commission cannot be held responsible for any use which may be made of the information contained therein).

\section{REFERENCES}

[1] Mone, M A., McKinley, W. and Baiker, V. L. (1998). 'Organizational decline and innovation: a contingency framework'. Academy of Management Review, 23,115-32.

[2] Croasan, M. M. and Apaydin, M. (2010). 'A multi-dimensional framework of organizational innovation: a systematic review of the literature'. Journal of Management Studies, 47,1154-91. https://doi.org/10.1111/j.1467-6486.2009.00880.x

[3] Kaisto-Mertancn, L. \& Mertanen, 0. (20121 Innovation pedagogy- a new culture for education. Revista de Docencia Universitaria (10), 6786.ISSN:1887-4592, http://redu.ne*/re\&ilindcx.php'REDU/arúcle/view/333

[4] Marin-Garcia, J. A., Aznar-Mas, L. E. \& González-Ladrón de Gevara, F. (2011). Innovation types and talent management for innovation. Working Papera en Operationa Management,2, (2), 25-

[5] Marin-Garcia J.A. ; Pérez-Peñalver, María José.; Vidal-Carreras, PI.; Maheut, J. (2012). How to assess the innovation competency of higher education students. Proceedings of the 7th International Conference on Industrial Engineering and Industrial Management, p.p.: 920-928.

Retrieved from : http://www.insisoc.org/CIO2013/papers/EN07\%20E/How\%20to\%20Assess\%20the\%20Innovation\%20Competency $\% 20$ of $\% 20$ Higher\%20Education\%20Students.pdf

[6] Penttilä, T. \& Kairisto-Mertanene, L. (2012). Innovation competence barometer ICB - a tool for assessing students' innovation competences as learning outcomes in higher education, in INTED2012 Conference. 5th-7th March 2012, pp. 6347-6351.
[7] Marin-Garcia, J.A., Andreu Andres, M., Atares-Huerta, L, Aznar'.Mas, L., Garcia-Carbondli, A., González-Ladrón-de.Gevara, F., Montero Fleta, B., Perez-Petialver, M, \& Watts, F. (2016). Proposal of a Framework for Innovation Competencies Development and Assessinent (FINCODA). WPOM-Wosking Papers on Operations Managament, 7(2). 119-126. di:httpJIdx.doi.orgI10.4995/sypom.v7i2.6472Berdrow, 1.

[8] Cerinšek, G. \& Dolinsek, S. (2009). Identifying employees' innovation competency in organisations». International Journal of Innovation and Learning, 6, (2), 164-177. https://doi.org/10.1504/IJIL.2009.022811

[9] De Jong, J. P. J., Kemp, R. (2003) «Determinants of CoWorkers' Innovative Behaviour: An Investigation into Knowledge Intensive Services». International Journal of Innovation Management, Vol. 07, $\mathrm{n}^{\circ}$. 02, pp. 189-212.

https://doi.org/10.1142/S1363919603000787

[10] Kessler, E. H. (2004). Organizational innovation: A multi-level decision-theoretic Perspective. International Journal of Innovation Management, 8, (3), 275-295.Alloway, A. (1997). Be prepared with an affinity diagram. Quality Progress, 30(7), 75-77. Retrieved from http://www.scopus.com/inward/record.url?eid=2-s2.0-

0031190504\&partnerID=40\&md5=6c32d2393401409441e40ac990f6ef $4 \mathrm{a}$

[11] Lehto, A., Kairisto-Mertanene, L. \& Penttilä, T. (2011). Towards innovation pedagogy. A new approach to teaching and learning for universities of applied sciences. Turku University of Apllied Sciences. Turku.

[12] Pentillä, T., Kairisto-Mertanen, L. \& Putkonen, A. (2011). Messages of innovation pedalogy, in Lehto, A., Kairisto-Mertanene, L. \& Penttilä, T. (Eds.), Towards innovation pedagogy. A new approach to teaching and learning for universities of applied sciences. Turku University of Apllied Sciences. Turku.

[13] Watts, F., Garcia-Carbonell, A., \& Andreu Andrés, M. A. (2013). Innovation competencies development: Incode barometer and use guide. Turku: Turku University od Applied Sciences.

[14] Santos, G. 2006. Card sort technique as a qualitative substitute for quantitative exploratory factor analysis. Corporate Communications 11(3), 288-302. https://doi.org/10.1108/13563280610680867

[15] Burtner, R., May, R., Scarberry, R., LaMothe, R., \& Endert, A. (2013). Affinity+: Semi-Structured Brainstorming on Large Displays. POWERWALL: International Workshop on Interactive, Ultra-HighResolution Displays, Part of the SIGCHI Conference on Human Factors in Computing Systems, CHI '13 Extended Abstracts on Human Factors in Computing Systems (CHI EA '13), 1-6.

[16] Kawakita, J. (1991). The original kj method. Tokyo: Kawakita Research Institute.

[17] Alloway, A. (1997). Be prepared with an affinity diagram. Quality Progress,30(7), $\quad 75-77 . \quad$ Retrieved from http://www.scopus.com/inward/record.url?eid=2-s2.00031190504\&partnerID=40\&md5=6c32d2393401409441e40ac990f6ef $4 \mathrm{a}$

[18] Awasthi, A. \& Chauhan, S.S. (2012). A hybrid approach integrating affinity diagram, AHP and fuzzy TOPSIS for sustainable city logistics planning. Applied Mathematical Modelling, 36 (2012) 573-584. https://doi.org/10.1016/j.apm.2011.07.033

[19] Onwuegbuzie, A. J., Bustamante, R. M. \& Nelson, J. A. (2009). Mixed Research as a Tool for Developing Quantitative Instruments. Journal of Mixed Methods Research, 4, (1), 56-78. https://doi.org/10.1177/1558689809355805

[20] Widjaja, W., Yoshii, K., Haga, K., \& Takahashi, M. (2013). Discusys: Multiple user real-time digital sticky-note affinity-diagram brainstorming system. Procedia Computer Science, 22(0), 113-122. http://doi.org/10.1016/j.procs.2013.09.087W.-K. Chen, Linear Networks and Systems (Book style). Belmont, CA: Wadsworth, 1993, pp. 123-135.

[21] Gioia, D. A., Corley, K. G., \& Hamilton, A. (2012). Seeking qualitative rigor in inductive research: Notes on the Gioia methodology. Organizational Research Methods. doi: 10.1177/1094428112452151. https://doi.org/10.1177/1094428112452151

[22] Lizasoain, L. \& Joaristi, L. (2012). Las nuevas tecnologías y la investigación educativa. El análisis de datos de variables categoriales. Revista Española de Pedagogía 251, 111- 130. 
[23] Watts, F., Marin-Garcia, J.A., Garcia-Carbonell, A. \& Aznar-Mas, L.E. (2012) Validation of a rubric to assess innovation competence. Working Papers on Operations Management 3: 61-70. https://doi.org/10.4995/wpom.v3i1.1159

[24] Hair, J. F., Hult, G. T., Ringle, C. M., \& Sarstedt, M. (2013). A Primer on Partial Least Squares Structural Equation Modeling (PLS-SEM). Thousand Oaks: Sage.

[25] Marin-Garcia, J. A., Perez-Peñalver, M. J., \& Watts, F. (2013). How to assess innovation competence in services: The case of university students. Direccion y Organizacion (50), 48-62. Retieved from : http://www.revistadyo.com/index.php/dyo/article/viewFile/431/451

PhD. Mónica Martínez-Gómez, is a lecturer at the Universitat Politècnica de València, Valencia (Spain). She lectures on statistics, operations research and quality in Industrial Engineering and Business Management degrees. Her main research interests are multivariate techniques, especially structural equation model, performance evaluation and active learning in higher education.

Manuel Marí Benlloch, is an associate professor at the Universitat Politècnica de València (Spain). She lectures on statistics, operations research and quality in Industrial Engineering and Business Management degrees and master. His main research interests are multivariate techniques, performance evaluation and active learning in higher education.

PhD. Juan A. Marin-Garcia is a lecturer at the Universitat Politécnica de València (Spain). He lectures on management, teamwork and human resources management in Industrial Engineering and Business Management degrees. His main research fields are participative management, continuous improvement, lean manufacturing systems, performance evaluation and active learning in higher education. 